\title{
PLATELET ADHESION STUDIES ON DIPYRIDAMOLE COATED POLYURETHANE SURFACES
}

\author{
Yvette B.J. Aldenhoff and Leo H. Koole* \\ Centre for Biomaterials Research, University of Maastricht, PO Box 616, \\ 6200 MD Maastricht, The Netherlands.
}

\begin{abstract}
Surface modification of polyurethanes (PUs) by covalent attachment of dipyridamole $\left(\right.$ Persantin $\left.^{\circledR}\right)$ is known to reduce adherence of blood platelets upon exposure to human platelet rich plasma (PRP). This effect was investigated in further detail. First platelet adhesion under static conditions was studied with four different biomaterial surfaces: untreated PU, PU immobilised with conjugate molecule $\mathbf{1}$, PU immobilised with conjugate molecule $\mathbf{2}$, and PU immobilised with conjugate molecule 3. In PU immobilised with 1 dipyridamole is directly linked to the surface, in PU immobilised with $\mathbf{2}$ there is a short hydrophilic spacer chain in between the surface and the dipyridamole, while conjugate molecule $\mathbf{3}$ is merely the spacer chain. Scanning electron microscopy (SEM) was used to characterise platelet adhesion from human PRP under static conditions, and fluorescence imaging microscopy was used to study platelet adhesion from whole blood under flow. SEM experiments encompassed both density measurements and analysis of the morphology of adherent platelets. In the static experiments the surface immobilised with $\mathbf{2}$ showed the lowest platelet adherence. No difference between the three modified surfaces emerged from the flow experiments. The surfaces were also incubated with washed blood platelets and labeled with Oregon-Green Annexin V. No capture of Oregon-Green Annexin V was seen, implying that the adhered platelets did not expose any phosphatidyl serine at their exteriour surface.
\end{abstract}

Key Words: Platelets, polyurethane, dipyridamole, blood compatibility.

"Address for correspondence:

L.H. Koole

Centre for Biomaterials Research

University of Maastricht

P.O. Box 616

6200 MD Maastricht

Tel: +31(0) 433881531

Fax: +31 (0) 433884159

E-mail:1.koole@bioch.unimaas.nl
Introduction

Polyurethanes find widespread use as construction biomaterials for catheters, blood pumps (Coumbe and Graham, 1994), and other medical devices, which are temporarily in contact with the circulation. The physi$\mathrm{cal} /$ mechanical properties of polyurethanes, including their high flexural strength and excellent resistance to flex fatigue, are particularly suitable for these applications (Boretos, 1981; Lelah and Cooper, 1986; Herring et al., 1994; Müller and Dasbach, 1994). Polyurethanes have, however, one major drawback: they have only moderate blood compatibility. Surface-induced thrombus formation poses a significant problem in the development of improved cardiovascular devices, which are based on polyurethanes.

We have shown previously, that the drug dipyridamole can be immobilised onto polyurethane surfaces, via a photochemical procedure (Aldenhoff and Koole, 1995; Aldenhoff et al., 1997a,b). Dipyridamole is a well-known non-toxic vasodilator and a powerful inhibitor of platelet activation/ aggregation; its generic name is Persantin ${ }^{\circledR}$ (Oates et al., 1987; Singh et al., 1994). Two conclusions emerged from our previous work: $(i)$, surface-bound dipyridamole renders the surface significantly less thrombogenic, and (ii), adherence of bloodplatelets is markedly reduced through this surface modification.

Here we report the results of an extended study on dipyridamole-modified polyurethane medical grade foils. Three sets of these foils were treated with either $\mathbf{1 , 2}$ or $\mathbf{3}$ (Figure 1); a fourth set was used as untreated controls. Note that compounds 1-3 are conjugate molecules. Molecules $\mathbf{1}$ and $\mathbf{2}$ consist of a protected dipyridamole unit, which is linked to a photoreactive $p$-azidobenzoyl ester (Leyva et al., 1986; Li et al., 1988; Smith, 1984), either directly (1), or via a short hydrophilic spacer chain, (2). Compound $\mathbf{3}$ served to study the effect of the hydrophilic spacer chain per se.

Each of the four surfaces was incubated with platelet-rich human blood plasma (PRP), for 15,30 or 60 minutes. The density of the adhered bloodplatelets was studied as a function of time. The morphological changes of the adhered bloodplatelets were studied in the static model using PRP (Ko et al., 1993; Frank et al., 2000). Using whole blood, platelet adhesion was also studied with fluorescent microscopic techniques (Billy et al., 1997; Briedé et al., 1999). In addition, the surfaces were incubated with washed platelets, labeled with Oregon-Green Annexin V, in an attempt to answer the question whether or not the adhered platelets expose phosphatidyl serine at the exteriour plasma membrane (Billy et al., 1997; 


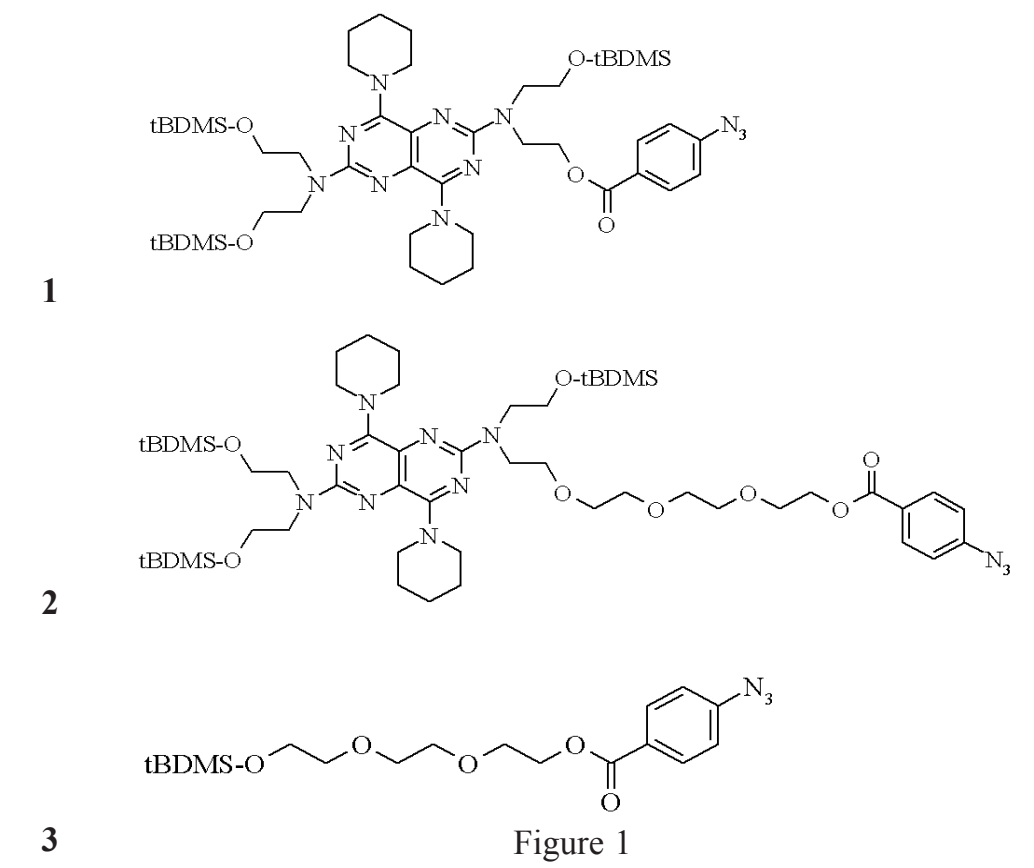

Briedé et al., 1999; van Engeland et al., 1998; Stuart et al., 1995).

\section{Materials and Methods}

\section{General}

All solvents and starting materials were of the highest available purity or were purified as specified. $N, N$ dimethylformamide, pyridine and tetrahydrofuran were distilled from calcium hydride and stored over Linde $3 \AA$ molecular sieves. Triethylamine was distilled from calcium hydride and stored over potassium hydroxide pellets. Thin layer chromatography was performed on glass plates $(3 \times 10 \mathrm{~cm})$ with a fluorescent indicator. Silica gel 60 (particle size $0.063-0.200 \mathrm{~mm}$ ) was used for column chromatography. ${ }^{1} \mathrm{H}$ Nuclear Magnetic Resonance (NMR) and ${ }^{13} \mathrm{C}$ NMR were recorded at 399.9 and $100.6 \mathrm{MHz}$, respectively, on a Varian (Palo Alto, CA) Unity-Plus spectrometer, using deuterated chloroform or deuterated methyl sulfoxide as the solvent. Tetramethylsilane was used at the internal reference $(\delta=0.00 \mathrm{ppm})$. Conjugates $\mathbf{1}$ and 2 were prepared as described previously (Aldenhoff and Koole, 1995; Aldenhoff et al., 1997a).

\section{Preparation of $\boldsymbol{p}$-azidobenzoyl chloride}

A solution of $p$-azidobenzoic acid ( $7.50 \mathrm{~g}, 45.98 \mathrm{mmol})$ (Bretschneider and Rager, 1950) and thionyl chloride (16.29 g, $138.04 \mathrm{mmol}$ ) in $250 \mathrm{~mL}$ of anhydrous tetrahydrofuran was refluxed for $30 \mathrm{~min}$. All volatiles were removed under reduced pressure (in the hood, stench). The solid residue was recrystallized from hexane to give pure $p$-azidobenzoyl chloride as a yellowish solid. Yield: $6.67 \mathrm{~g}(81 \%) .{ }^{1} \mathrm{H} \mathrm{NMR}\left(\mathrm{CDCl}_{3}\right), \delta: 8.05(2 \mathrm{H}, \mathrm{d}$, aromatic $\mathrm{H}), 7.05\left(2 \mathrm{H}, \mathrm{d}\right.$, aromatic H); ${ }^{13} \mathrm{C}$ NMR (DMSO-d $), \delta$ : $166.39,143.87,131.15,127.20,119.34,119.05$. (DMSO $=$ dimethylsulfoxide)

\section{Preparation of compound 4}

To a magnetically stirred solution of triethylene glycol (33.08 g, $220.28 \mathrm{mmol})$ and dimethylamino pyridine $(0.17 \mathrm{~g}, 1.38 \mathrm{mmol})$ in $100 \mathrm{~mL}$ of anhydrous pyridine was added $p$-azidobenzoyl chloride in 10 portions during a time period of 3 hours. The solution was stirred overnight under exclusion of moisture. Then, all volatiles were removed under reduced pressure (last traces of pyridine were coevaporated with toluene). The residue was taken up in dichloromethane and washed with saturated aqueous sodium bicarbonate (three times) and water (three times). The organic layer was dried on magnesium sulfate, filtered, and concentrated to dryness under reduced pressure. The crude product was purified by column chromatography eluting with ethyl acetate to give compound 4 as a viscous oil. Yield: $4.22 \mathrm{~g}(52 \%) ; \mathrm{R}_{\mathrm{f}}$ (ethyl acetate): 0.34; ${ }^{1} \mathrm{H}$ NMR $\left(\mathrm{CDCl}_{3}\right), \delta: 8.05(2 \mathrm{H}, \mathrm{d}$, aromatic $\mathrm{H}), 7.05$ $(2 \mathrm{H}, \mathrm{d}$, aromatic $\mathrm{H}), 4.42\left(2 \mathrm{H}, \mathrm{t}, \mathrm{CH}_{2}-\mathrm{O}(\mathrm{CO})\right), 3.79(2 \mathrm{H}$, $\left.\mathrm{t}, \mathrm{CH}_{2}-\mathrm{CH}_{2}-\mathrm{O}(\mathrm{CO})\right), 3.64\left(6 \mathrm{H}, \mathrm{m}, \mathrm{CH}_{2}-\mathrm{O}\right), 3.56(2 \mathrm{H}, \mathrm{t}$, $\left.\mathrm{CH}_{2}-\mathrm{O}\right), 2.78(1 \mathrm{H}, \mathrm{t}, \mathrm{OH}) ;{ }^{13} \mathrm{C} \mathrm{NMR}\left(\mathrm{CDCl}_{3}\right), \delta: 165.21$, 144.32, 131.01, 126.05, 118.31, 72.06, 70.17, 69.85, $68.69,63.53,61.20$.

\section{Preparation of compound 3}

To a solution of compound 4 (3.74 g, $12.67 \mathrm{mmol})$ in $75 \mathrm{~mL}$ anhydrous dimethyl formamide was added dimethylamino pyridine $(3.09 \mathrm{~g}, 25.33 \mathrm{mmol})$, anhydrous triethyl amine $(2.56 \mathrm{~g}, 25.33 \mathrm{mmol})$ and tertbutyldimethylsilyl chloride (3.82 g, $25.33 \mathrm{mmol})$. The reaction mixture was magnetically stirred for 1 hour under exclusion of moisture. Then, brine was added and the mixture was extracted with diethyl ether (three times). The diethyl ether layer was washed with saturated aqueous ammonium chloride (three times). The organic layer was dried on magnesium sulfate, filtered and concentrated to dryness under reduced pressure. The crude product was purified by column chromatography eluting with ethyl 
acetate to give 3 as a viscous oil. Yield: $5.12 \mathrm{~g}(99 \%) ; \mathrm{R}_{\mathrm{f}}$ (ethyl acetate): 0.69; ${ }^{1} \mathrm{H} \mathrm{NMR}\left(\mathrm{CDCl}_{3}\right), \delta: 7.98(2 \mathrm{H}, \mathrm{d}$, aromatic $\mathrm{H}), 6.98(2 \mathrm{H}, \mathrm{d}$, aromatic $\mathrm{H}), 4.40\left(2 \mathrm{H}, \mathrm{t}, \mathrm{CH}_{2}-\mathrm{O}(\mathrm{CO})\right)$, $3.77\left(2 \mathrm{H}, \mathrm{t}, \mathrm{CH}_{2}-\mathrm{CH}_{2}-\mathrm{O}(\mathrm{CO})\right), 3.69$ (2H, t, $\mathrm{CH}_{2}$-OtBDMS), 3.62 (4H, m, CH $-\mathrm{O}), 3.49\left(2 \mathrm{H}, \mathrm{t}, \mathrm{CH}_{2}-\mathrm{O}\right), 0.84(9 \mathrm{H}, \mathrm{d}, t-$ $\mathrm{Bu}-\mathrm{Si}), 0.00$ (6H, d, Me-Si); ${ }^{13} \mathrm{C} \mathrm{NMR}\left(\mathrm{CDCl}_{3}\right), \delta: 165.41$, 144.52, 131.29, 126.43, 118.53, 72.49, 70.54, 70.50, 68.97, $63.99,62.51,25.69,25.48,-3.76,-5.50$.

\section{Preparation of modified polyurethane surfaces}

Throughout the experiments a medical grade polyurethane foil (Pellethane D-55) was used. The foil is transparent and has a smooth surface, the thickness of the foils is $0.4 \mathrm{~mm}$. Pieces of $5 \times 5 \mathrm{~cm}$ were used. Stock solutions of the conjugate molecules were prepared in isopropanol (concentration $1 \mathrm{mM}$ ). The solution was sprayed (a compressedair sprayer was used) onto the polyurethane foils 20 times. After each spray the surfaces were dried with a hot-air föhn (to evaporate the isopropanol). Then, the surfaces were irradiated for $15 \mathrm{~min}$, at a distance of $30 \mathrm{~cm}$, with a medium metal halide lamp (Philips, Eindhoven, The Netherlands; HPA 1000 high-power Ultraviolet (UV) lamp), emitting radiation mainly between 300 and $400 \mathrm{~nm}$ (radiation output measured at $1.00 \mathrm{~m}$ distance in $\mu \mathrm{W} / \mathrm{cm}^{2}$ : UV-A: 1000 ; UV-B: 320; UV-C: 50) (van der Heiden et al., 1998). After irradiation the foils were thoroughly washed with isopropanol ( $3 \times 15 \mathrm{~min}$, with ultrasonic shaking) to remove all the unreacted compounds, and immersed into a solution of tetrabutylammonium fluoride $(8.0 \mathrm{~g})$ in nitromethane $(400$ $\mathrm{mL}$ ) to remove the tert-butyldimethylsilyl protecting groups. The surfaces were then washed extensively with isopropanol (2 x $30 \mathrm{~min})$ and water ( $2 \times 30 \mathrm{~min})$, dried, and stored in dry form before use.

\section{Adhesion of blood platelets in a static model}

Fresh blood was taken from a healthy donor (male, age 42 years) who has not been taken aspirin or any other anticoagulant one week prior to blood donation. The whole blood was anticoagulated with citrate $(0.13 \mathrm{mM})$ prior to the experiments. The blood was centrifuged at $250 \mathrm{~g}$ for $15 \mathrm{~min}$ at room temperature, and the PRP was decanted. The surfaces were incubated with $0.5 \mathrm{~mL}$ PRP at $37^{\circ} \mathrm{C}$ for 15,30 and 60 minutes. Then, the PRP was removed and the surfaces were washed with $0.1 \mathrm{M}$ phosphate-buffered saline (PBS-buffer, $\mathrm{pH}=7.2$, three times) to remove the non-adhered blood platelets. The adhered blood platelets were fixed with glutaraldehyde (2.5\% in PBS-buffer) for 3 hours at 4 ${ }^{\circ} \mathrm{C}$. The surfaces were dehydrated with ethanol series, dried in air, and sputter-coated (SC sputter coater 500, Bio-rad) with gold for $2 \mathrm{~min}$. The surfaces were subjected to scanning electron microscopy (SEM, PSEM 75, Goffin Meyvis, Overijse, Belgium; accelerating voltage $15 \mathrm{kV}$ ) to study the morphology of the adhered platelets.

\section{Platelet count}

For each surface, five rectangular fields if view were chosen randomly; the dimensions were 116 x $91 \mu \mathrm{m}$. Adhered platelets were counted manually, and the average densities of the adhered platelets per square mm were calculated from these data.

\section{Platelet morphology}

The adhered platelets on each of the rectangular fields of view, described above, were examined and classified according to the scheme of Ko et al. (1993) and Frank et al. (2000). This literature provides examples of the five different morphologies (Round (R), Dendritic (D), Spread Dendritic (SD), Spread (S), and Fully Spread (FS)) of adherent platelets.

\section{Platelet adhesion under flow}

Fresh blood from a healthy donor (male, age 42 years) was used, the blood was heparinized $(5 \mathrm{U} / \mathrm{mL})$, calcein $(2.5 \mu \mathrm{M})$ was added during $25 \mathrm{~min}$. at $37^{\circ} \mathrm{C}$. The surfaces were immersed in $20 \mathrm{mM} \mathrm{N}-(2-$ hydroxyethyl)piperazine-N'-(4-butanesulfonic acid) (HEPES, $\mathrm{pH}=7.5$ ) buffer for $30 \mathrm{~min}$. The (whole) blood was run over the surfaces at a shear rate of $100 \mathrm{l} / \mathrm{s}$ (flowrate $200 \mu \mathrm{L} / \mathrm{min}$ ) for $10 \mathrm{~min}$. The experiment was followed by a video system and at several time intervals video-images were stored.

\section{Platelet activation}

A suspension of washed platelets was prepared as described previously (Briedé et al., 1999). The four different surfaces were incubated with a suspension of 5 x $10^{7}$ platelets $/ \mathrm{mL}$. Oregon-Green Annexin V $(1 \mathrm{mg} / \mathrm{ml})$ was used to detect possible exposure of phosphatidyl serine on the outer surface of activated platelets (Briedé et al., 1999).

\section{Fluorescence imaging microscopic system}

A parallel-plate chamber as described by Sakariassen et al. was used as the perfusion chamber throughout these experiments (Sakariassen et al., 1983). Positive phase-contrast transmission images were obtained with an inverted microscope (Nikon Diaphot 200; Nikon, Tokyo, Japan) using a Nikon $100 \mathrm{X}$ quartz oil-immersion objective containing a phase plate. The phase-contrast transmission images were recorded with an infrared camera (VPM 6132 monochrome high-resolution charge-coupled device camera, Vista, Norbain, UK). For fluorescence imaging, light from a xenon lamp passed a computer controlled excitation and neutral density wheel, and reached the objective of the inverted microscope through an UV-transparent liquid light guide and a dichroic long-pass filter. The emission light passed a computer-controlled emission wheel, and finally reached a low-light level intensified, charge-coupled device camera working at standard video rate (Photonic Sciences, Robertsbridge, UK). The fluorescence images were digitized and averaged; background images were substracted and stored.

\section{Results and Discussion}

The chemical synthesis of conjugate molecule 3 proceeded smoothly. The synthesis route is outlined in Figure 2. First $p$-azidobenzoic acid was converted in $p$ azidobenzoyl chloride with thionyl chloride. Then, triethylene glycol was reacted with $p$-azidobenzoyl chlo- 
<smiles>Cc1cc(C(=O)OCCOCCOCCOCCc2cc(C(=O)Cl)ccc2N)ccc1N</smiles>

Figure 2. Preparation of compound 3.

ride in pyridine.

Pure 4 was obtained after routine column chromatography on silica gel. In the last step 4 was reacted with tBDMS-Cl. The target compound $\mathbf{3}$ was obtained in pure form after column chromatography. The identity and purity of this compound, a colorless viscous oil, was established by ${ }^{1} \mathrm{H}$ NMR and ${ }^{13} \mathrm{C}$ NMR.

The photo-immobilisation of all three of the conjugate molecules was succesfull. For the surfaces immobilised with $\mathbf{1}$ and 2, the surface density was measured using UV-extinction, as described previously (Aldenhoff and Koole, 1995; Aldenhoff et al., 1997a). Briefly, the molar extinction coefficients of all conjugate molecules (in isopropanol) were determined at $\lambda=408$. A blank solution, containing a known area $\left(\mathrm{mm}^{2}\right)$ of PU in THF was prepared, and the blanco UV spectrum was stored in the digital memory of the UV spectrometer. Then, a known area $\left(\mathrm{mm}^{2}\right)$ of the PU, which had been immobilised with either conjugate molecule, was dissolved in THF and the UV spectrum was measured. The surface concentration of the immobilised conjugate molecules could be calculated from the UV absorption at $\lambda=408$. Surface densities of approximately $20 \mathrm{nmol} / \mathrm{cm}^{2}$ were found for both surfaces. For the surface immobilised with $\mathbf{3}$, it was found that the water contact angle decreased, from approximately $50^{\circ}$ for the untreated $\mathrm{PU}$ to $40^{\circ}$ for the treated PU, as a result of the surface modification. This implies that the surface immobilisation also proceeded with conjugate molecule 3.
Table 1 compiles the average densities of adhered platelets as a function of time. Figure 3 shows a graphical representation of these data. Figure 4 shows typical scanning electron micrographs of the four different surfaces at 30 minutes incubation. For the polyurethane and the surface immobilised with $\mathbf{1}$ it is clear that the longer the incubation time the more platelets adhere. For conjugate molecule $\mathbf{2}$ and $\mathbf{3}$, however, the density of adhered platelets seems to decrease after an incubation time of $30 \mathrm{~min}$. The amount of adhered blood platelets after 15 minutes increase in the following order: conjugate $\mathbf{2}<$ conjugate 1 $<$ unmodified PU $<$ conjugate $\mathbf{3}$. After 30 minutes the amount of adhered blood platelets increases as follows:

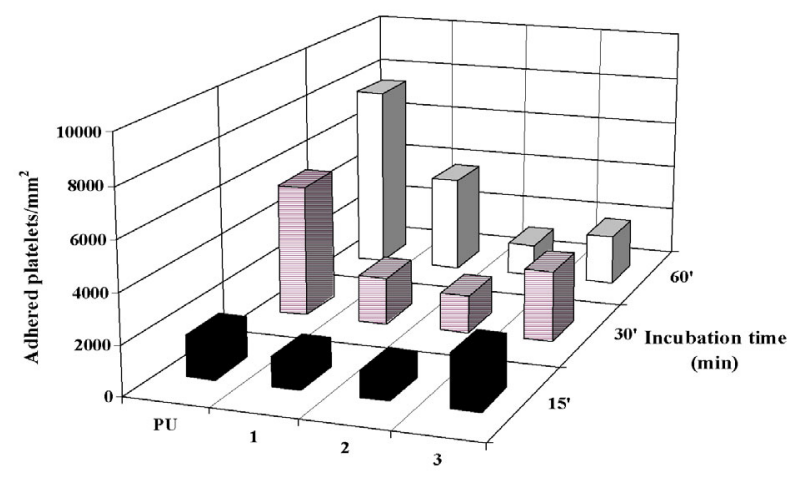

Figure 3. The density of adhered blood platelets on each of the four surfaces at different incubation times.

Table 1. Number of blood platelets per square $\mathrm{mm}$ and average shape distribution on each of the four different surfaces at different incubation times.

\begin{tabular}{|c|c|c|c|c|c|c|}
\hline Surface & $\begin{array}{l}\text { Total of adhered } \\
\text { platelets } \\
\mathrm{mm}^{2}\end{array}$ & $\begin{array}{l}\text { Round } \\
(\mathrm{R}) \\
\%\end{array}$ & $\begin{array}{l}\text { Dendritic } \\
\text { (D) } \\
\%\end{array}$ & $\begin{array}{l}\text { Spread Dendritic } \\
\text { (SD) } \\
\%\end{array}$ & $\begin{array}{l}\text { Spread } \\
(\mathrm{S}) \\
\%\end{array}$ & $\begin{array}{l}\text { Fully Spread } \\
\text { (FS) } \\
\%\end{array}$ \\
\hline PU-15' & $1640 \pm 378$ & 6 & 32 & 22 & 21 & 19 \\
\hline PU-30' & $5420 \pm 1279$ & 8 & 26 & 29 & 24 & 13 \\
\hline PU-60’ & $7640 \pm 2912$ & 2 & 20 & 27 & 36 & 15 \\
\hline 1-15 & $1180 \pm 277$ & 8 & 12 & 9 & 6 & 65 \\
\hline 1-30' & $1920 \pm 753$ & 7 & 29 & 14 & 15 & 35 \\
\hline $2-60$ & $3980 \pm 1482$ & 4 & 25 & 15 & 20 & 36 \\
\hline $2-15^{\prime}$ & $1040 \pm 477$ & 25 & 14 & 1 & 20 & 40 \\
\hline 2-30' & $1540 \pm 483$ & 14 & 21 & 11 & 26 & 28 \\
\hline $2-60$ & $1340 \pm 607$ & 9 & 28 & 6 & 30 & 27 \\
\hline 3-15, & $2140 \pm 1064$ & 23 & 27 & 12 & 12 & 26 \\
\hline 3-30' & $2900 \pm 886$ & 6 & 27 & 23 & 22 & 22 \\
\hline 3-60' & $2080 \pm 1291$ & 3 & 17 & 32 & 38 & 10 \\
\hline
\end{tabular}



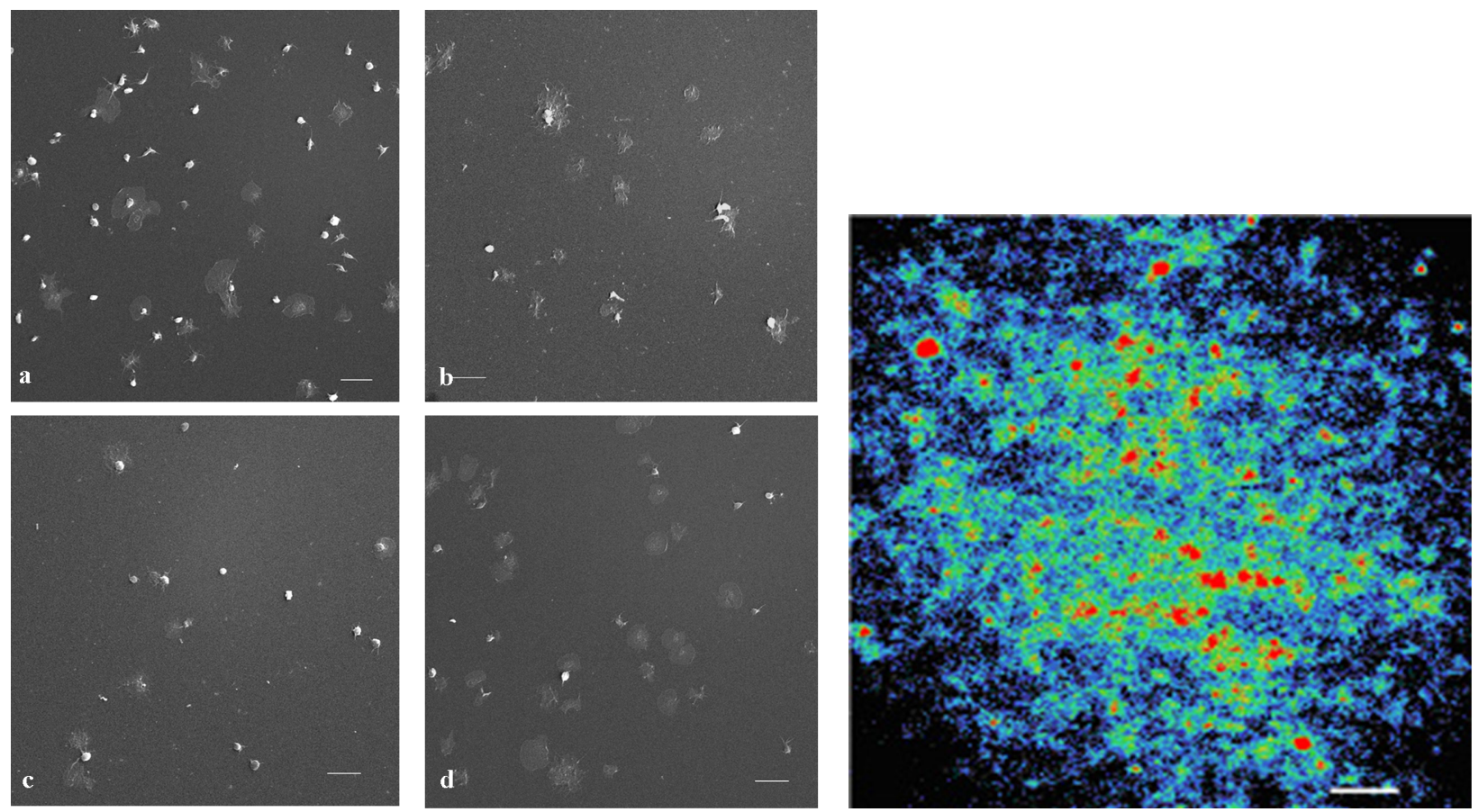

Figure 4. Typical scanning electron micrographs of A: unmodified PU; B: PU modified with 1; C: PU modified with 2; D: PU modified with 3, after an incubation time of 30 minutes. Length of bar $=10 \mu \mathrm{m}$.

Figure 5. Fluorescence images after a flow time of 10 minutes of unmodified PU. Length of bar $=10 \mu \mathrm{m}$ conjugate $\mathbf{2}<$ conjugate $\mathbf{1}<$ conjugate $\mathbf{3}<$ unmodified PU, and after 60 minutes: conjugate $\mathbf{2}<$ conjugate $\mathbf{3}<$ conjugate $\mathbf{1}<$ unmodified PU.

These data reveal that unmodified PU is the most adhesive surface. The surface immobilised with 2 shows lowest platelet adhesion, which is in agreement with previous data (Aldenhoff et al., 1997b). Moreover it is seen that the platelet density for PU modified with $\mathbf{2}$ does not increase with time.

The studies on platelet adhesion from heparinized full blood, under flow, revealed essentially the same trends. Because the platelets are labelled with the fluorescence dye calcein fluoresceine adherence of platelets onto the biomaterial leads to immobilised fluorescent acitvity. It is possible to monitor fluorescence in the field of view as a function of time. After 10 minutes, the fluorescent area on the untreated PU was $35 \pm 10 \%$. Figure 5 shows the fluorescence image of the unmodified PU. For the three other surfaces, hardly any platelet adhesion was found after 10 minutes. This means that all the three surface modifications performed equally well in this test. Overall, the data from the fluorescence experiments under flow are in line with the results from the SEM experiments.

The SEM micrographs could also be used to study the morphology of the adhered platelets, and also the changes in morphology as a function of incubation time. In order to characterise the morphology of the adhered platelets, we used the same classification in platelet shape as described by Ko et al. (1993 and Frank et al. (2000). Five stages of shape changes were distinguished: (1) round or discoid (R), no pseudopodia present, (2) dendritic (D), early pseudopodial, no flattening (3) spread dendritic (SD), one or more pseudopodia flattenend, no hyaloplasm be- tween pseudopodia; (4) spread (S), late pseudopodial, hyaloplasm spreading; and (5) fully spread (FS), hyaloplasm fully spread, no distinct pseudopodia. The results of this analysis are compiled in Table 1 and represented graphically in Figures 6A-C. The data show that platelets in the "round" state are most abundant after 15 minutes incubation: their relative contribution decreases gradually with time. Furthermore, it appears that the surfaces that expose dipyridamole at their surface have relatively high numbers of spread and fully spread platelets, already after 15 minutes incubation (65\% for immobilized 1, and $40 \%$ for immobilised 2 ). The latter conclusion made us wonder what was actually happening: $(i)$ do the platelets spread because they are activated by the dipyridamole surface, or ( $i i)$ do the platelets spread because of a favourable interaction with the surface? In an attempt to discriminate between these two alternatives, a suspension of washed human platelets was mixed with Oregon-Green Annexin V. This mixture was used in a FIMS experiment as described above, using the surfaces that were treated with conjugate molecules $\mathbf{1}$ or $\mathbf{2}$. Annexin $\mathrm{V}$ is known to form a complex with phosphatidyl serine, which is exposed on the exteriour plasma membrane of activated platelets. So if the adhered platelets retain the OregonGreen Annexin V, this implies that the platelets expose phosphatidylserine. After 10 minutes, hardly any Oregon Green label could be detected on both surfaces, which implies that the adherent platelets do not expose phosphatidylserine (van Engeland et al., 1998; Stuart et al., 1995). We assume, therefore, that the adherent platelets are not activated. We envisage two possible explanations for this phenomenon: $(i)$ either the immobilised dipyridamole molecules are recognized by anchoring molecules 

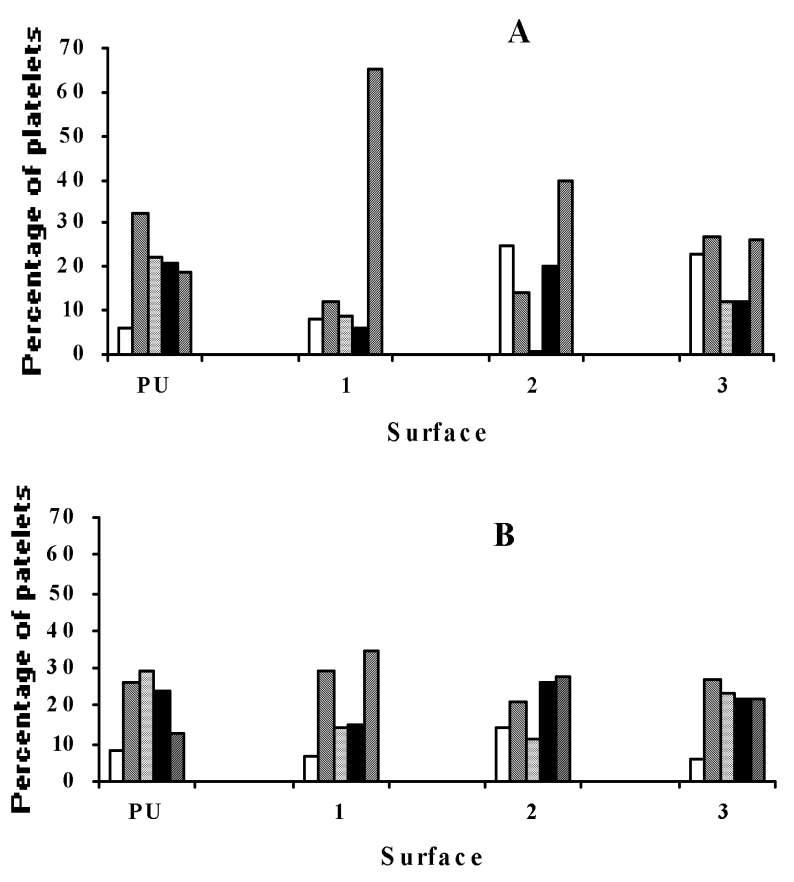

$\square$ R $\square$ D $\square$ SD $\square$ S $\square$ FS

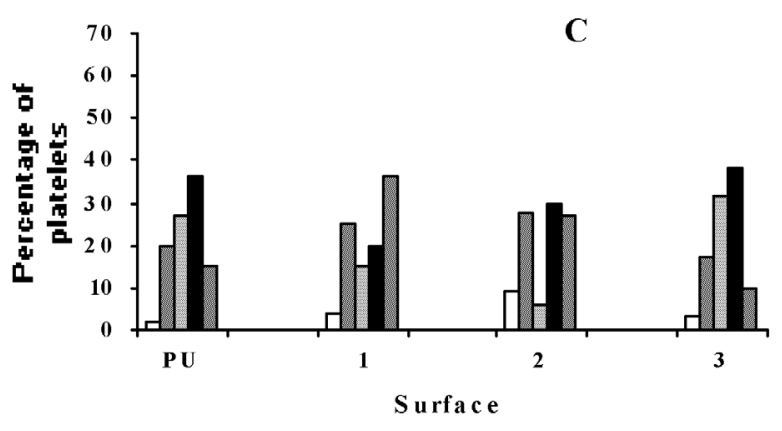

Figure 6. Distribution of the different stages of the adhered blood platelets at an incubation time of A: 15 minutes; B: 30 minutes; C: 60 minutes. Platelet shapes: $\mathrm{R}=$ round; $\mathrm{D}=$ dendritic; $\mathrm{SD}=$ spread dendritic; $\mathrm{S}=$ spread; $\mathrm{FS}=$ fully spread.

on the platelet's surface, $(i i)$ or the immobilised dipyridamole molecules change the physical surface properties of the surface which may in turn, affect the adsorption of plasma proteins in such a way that a more passive surface is obtained.

\section{Conclusion}

Photochemical immobilisation of dipyridamole provides a means to decrease adhesion of bloodplatelets, both under static and dynamic conditions. Use of the control molecule 3 , which is merely the spacer molecule without dipyridamole, helped to draw this conclusion. The exact mechanism of action of immobilised dipyridamole remains unclear: the effect may be based on platelet-dipyridamole recognition, or immobilised dipyridamole may affect adsorption of plasma proteins prior to platelet adhesion.

\section{Acknowledgement}

We thank Dr. Jacco Briedé and Dr. Theo Lindhout for performing the platelet adhesion experiments under flow and the platelet activation experiments.

\section{References}

Aldenhoff YBJ, Koole LH (1995) Studies on a new strategy for surface modification of polymeric biomaterials. J Biomed Mater Res 28: 917-928.

Aldenhoff YBJ, Blezer R, Lindhout T, Koole LH (1997a) Photo-immobilization of dipyridamole $\left(\right.$ Persantin $\left.{ }^{\circledR}\right)$ at the surface of polyurethane biomaterials: reduction of in vitro thrombogenicity. Biomaterials 18: 167-172.

Aldenhoff YBJ, Pijpers AP, Koole LH (1997b) Synthesis of a new photoreactive derivative of dipyridamole and its use in the manufacture of artificial surfaces with low thrombogenicity. Bioconjugate Chem 8: 296-303.

Billy D, Briedé J, Heemskerk JWM, Hemker HC, Lindhout T (1997) Prothrombin conversion under flow conditions by prothrombinase assembled on adherent platelets. Blood Coagul and Fibrinolysis 8: 167-174.

Briedé J, Heemskerk JWM, Hemker HC, Lindhout T (1999) Heterogeneity in microparticle formation and exposure of anionic phospholipids at the plasma membrane of single adherent platelets. Biochim Biophys Acta 1251: 163-172.

Boretos JW (1981) The chemistry and biocompatiblity of specific polyurethane systems for medical use. In: Biocompatibility of Clinical Implant Materials. DF Williams (ed). CRC Press, Boca Raton, Fl. pp 127-144.

Bretschneider H, Rager H (1950) Darstellung aromatischer azido verbindungen nach der DuttWormallschen reaktion (Synthesis of aromatic azido compounds according to the Dutt-Wormall reaction). Monatsh Chem 8: 970-980 .

Coumbe A, Graham TR (1994) The pathology of artificial hearts and ventricular assist devices. In: The Pathology of Devices. CL Berry (ed). Springer Verlag, Berlin-Heidelberg. pp 161-198.

Frank RD, Dresbach H, Thelen H, Sieberth H-G (2000) Glutardialdehyde induced fluorescence technique (GIFT): A new method for the imaging of platelet adhesion on biomaterials. J Biomed Mater Res 52: 374-381.

Herring M, Smith J, Dalsing M, Glover J, Compton R, Etchberger K, Zollinger T (1994) Endothelial cell seeding of polytetrafluoroethylene femoral popliteal bypasses: The failure of low-density seeding to improve patency. J Vasc Surg 20: 650-655.

Ko T-M, Lin J-L, Cooper SL (1993) Surface characterization and platelet adhesion studies of plasma-sulphonated polyethylene. Biomaterials 12: 657-664.

Lelah MD, Cooper SL (1986) Polyurethanes in Medicine. CRC Press, Boca Raton, FL.

Leyva EL, Platz MS, Persy G, Wirtz JJ (1986) Photochemistry of phenyl azide: the role of singlet and triplet 
phenylnitrene as transient intermediates. J Am Chem Soc 108: 3783-3790.

Li Y-Z, Kirby JP, George MW, Poliakoff M, Schuster GB (1988) 1,2-didehydroazepines from the photolysis of substituted aryl azides: analysis of their chemical and physical properties by time-resolved spectroscopic methods. J Am Chem Soc 110: 8092-8098.

Müller KM, Dasbach G (1994) The pathology of vascular grafts. In: The Pathology of Devices. CL Berry (ed). Springer Verlag, Berlin-Heidelberg. pp 273-306.

Oates JA, Wood AJJ, Fitzgerald GA (1987) Medical intelligence drug therapy dipyridamole. N Engl J Med 316: $1247-1257$.

Sakariassen KS, Aarts PAMM, de Groot PG, Houdijk WPM, Sixma JJ (1983) A perfusion chamber developed to investigate platelet interaction in flowing blood with human vessel wall cells, their extracellular matrix and purified components. J Lab Clin Med 102: 522-535.

Singh JP, Rothfuss KJ, Wiernicki TR, Lacefield WB, Kurtz WL, Brown RF, Brune KA, Bailey D, Dubé GP (1994) Dipyridamole directly inhibits vascular smooth muscle cell proliferation in vitro and in vivo: implications in the treatment of restenosis after angioplasty. J Am Coll Cardiol 23: 665-671.

Smith PAS (1984) Aryl and heteroaryl azides and nitrenes. In: Azides and Nitrenes; Reactivity and Utility. EFV Scriven (ed). Academic Press, Orlando, FL. pp 95204.

Stuart MC, Bevers EM, Comforius P, Zwaal RF, Reutelingsperger CP, Frederik PM (1995) Ultrastructural detection of surface-exposed phosphatidyl-serine on activated platelets. Thromb Hemost 72: 1145-1151.

van der Heiden AP, Willems GM, Lindhout T, Pijpers AP, Koole LH (1998) Adsorption of proteins onto poly(ether urethane) with a phosphorylcholine moiety and influence of pre-adsorbed phospholipids. J Biomed Mater Res 20: 195-203.

van Engeland M, Nieland LJ, Ramaekers FC, Schutte B, Reutelingsperger CP (1998) Annexin V-affinity assay: a review on an apoptosis detection system based on phosphatidylserine experiments. Cytometry 31: 1-9.

\section{Discussion with Reviewers}

A. Curtis: Has the absence of unreacted azidocompounds in or on the foils been shown by analysis? Will the authors comment in the discussion as to whether these techniques could be used in real biomedical devices?

Authors: The azido compounds used to effect immobilization of dipyridamole to the polyurethane surface, become very reactive upon irradiation with ultraviolet light. Since the immobilization procedure involves irradiation with a high-intensity ultraviolet light lamp for more than 15 minutes, it is safe to assume that complete conversion of the azido compounds has been achieved. Furthermore, all surfaces were washed thoroughly, immediately after the irradiation. While the first washings showed little fluorescence, it was also obvious that no fluorescent molecules were eluted after $3-4$ washing steps.

Use of analytical techniques to "prove" the absence of unreacted azido compounds at the surface is technically very difficult. The most appropriate technique, probably, would be ESCA. The typical pattern of azido nitrogen could be used as a marker. It is clear, however, that this technique is very difficult to apply in our case, since there is very little azido compound to start with.

P. Descouts: It would have been nice to add SEM images of the different stages of platelets you have observed Authors: We agree with this reviewer, that SEM micrographs of the five different stages of platelet activation (round, dendritic, spread dendritic, spread, fully spread) would have been illustrative. We decided not to incorporate these pictures since they can be found in the literature. See, for instance, Ko et al. (1993), and Frank et al. (2000). 